Article

\title{
How Vulnerable Are Financial Markets to COVID-19? A Comparative Study of the US and South Korea
}

\author{
Wenbo Wang and Hail Park *(D) \\ Department of International Business and Trade, Kyung Hee University, Seoul 02447, Korea; \\ wangwenbo916@khu.ac.kr \\ * Correspondence: hailpark@khu.ac.kr; Tel.: +82-2-961-2170
}

Citation: Wang, W.; Park, H. How Vulnerable Are Financial Markets to COVID-19? A Comparative Study of the US and South Korea. Sustainability 2021, 13, 5587. https://doi.org/ $10.3390 /$ su13105587

Academic Editor: Francisco Guijarro

Received: 15 April 2021

Accepted: 12 May 2021

Published: 17 May 2021

Publisher's Note: MDPI stays neutral with regard to jurisdictional claims in published maps and institutional affiliations.

Copyright: (c) 2021 by the authors. Licensee MDPI, Basel, Switzerland. This article is an open access article distributed under the terms and conditions of the Creative Commons Attribution (CC BY) license (https:// creativecommons.org/licenses/by/ $4.0 /)$.

\begin{abstract}
In this study, we carry out a comparative analysis between the US and South Korea, with a special attention to three key areas, including the stock market, the currency market, and the bond market. By employing a composite model, VAR-GARCH-BEKK, we will attempt to capture both mean and volatility spillovers between the pandemic and financial markets, so as to explore the extent and ways in which the COVID-19 pandemic influences the financial sector. The empirical results provide substantial evidence in the following areas: (i) South Korea seems more vulnerable since all of its financial markets are seen to be statistically associated with the growth in infections. (ii) For the US, only the stock market is negatively impacted by the confirmed cases in terms of a conditional mean spillover model. (iii) According to the impulse response functions (IRFs), apart from the US dollar index, both the TED spread and stock returns respond significantly to innovations from the pandemic. (iv) There is little evidence to support the presence of volatility transmission from the pandemic to the financial markets in the two countries.
\end{abstract}

Keywords: COVID-19; VAR-GARCH-BEKK; return and volatility spillovers; financial markets; EMEs; advanced economies

\section{Introduction}

On 30 January 2020, the World Health Organization (WHO) declared a public health emergency of international concern in response to a coronavirus pandemic (COVID-19). Unlike Severe Acute Respiratory Syndrome (SARS) and Middle East Respiratory Syndrome (MERS), such an unprecedented event has not only raised concerns over health, but also over economic prospects including financial stability [1-3]. As of 31 August 2020, there were approximately 25 million confirmed cases of COVID-19 worldwide with a mortality rate of $3.54 \%$, covering more than 210 countries and regions. As the COVID-19 pandemic continues to spread around the world, a public health emergency has gradually deteriorated into an economic issue, which has raised disputes over its severity and duration. However, throughout history, financial crises, in most cases, were triggered by financial fragility.

This comparative study of the US and South Korea is motivated by several factors. To begin with, the US currently is the world's largest economy, whose financial hegemony is beyond controversy. A more sophisticated financial system and an effective transmission mechanism of monetary policy, to a great extent, enhance its abilities to fend off external risks. By contrast, in an attempt to impel capital market internationalization, the South Korean government just started deregulating its financial sector at the start of the 1980s. Unfortunately, almost without exception, South Korea's financial markets fell victim to the 1997-1998 Asian Financial Crisis (AFC) and 2008-2009 Global Financial Crisis (GFC), such that this small open economy has had to struggle with the problem of strengthening its ability to withstand external shocks. Therefore, it is worth studying whether the two financial markets' performance in the two economies tend to differ in response to the COVID-19 pandemic particularly in the initial stages of the pandemic. Subsequently, given the heterogeneity of the financial sector, the monetary authorities unanimously responded with 
stimulus measures to address uncertainty, albeit not with a unified strategy. For instance, to facilitate financial system liquidity, the two countries slashed the base rate and purchased Treasury Bonds. However, unlike the US, the Bank of Korea (BOK) simultaneously took measures to facilitate funding in foreign exchange. These measures could lead to somewhat different consequences in an advanced economy and an Emerging Market Economy (EME). Last but not least, despite the fact that expansionary policy, not surprisingly, is conducive to accelerating economic recovery in the short-run, there have been mounting concerns over the extent to which it may jeopardize the sustained financial stability in the mid- and longterm. More specifically, unconventional monetary policy, for instance, Quantitative Easing (QE), will drive up financial asset prices and further exacerbate both domestic and foreign financial markets' vulnerability to external and internal shocks, which could precipitate another recession [4,5]. Although the potential consequence of policy interventions will not be discussed in detail, hopefully, the aforementioned dilemma could arouse regulators' attention to policy assessment.

Remarkable contributions to the existing literature are at least threefold: (i) With a larger time series dataset, this study intends to quantify the impacts of COVID-19 on the financial sector, including stock markets, currency markets, as well as bond markets. (ii) We elaborate on parallels and differences between a representative advanced economy and an EME in terms of financial markets' reaction to the COVID-19 outbreak. (iii) By incorporating a conditional variance model into a conditional mean model, we analyze return spillovers, shock spillovers, and volatility spillovers among markets simultaneously.

The remainder of this study is organized as follows: Section 2 discusses the existing literature providing insight into the impact of COVID-19 on the financial sector in both EMEs and advanced economies, and the corresponding transmission mechanism. Section 3 provides a detailed description pertaining to data and model specification, followed by empirical results as well as interpretation in Section 4. The last section is concluding remarks.

Amid growing concerns over the unpredictability of global financial markets, there has been a shift in investors' attitude towards risk. Psychological and behavioral variations are not synchronized with changes in investment climate, and generally lag behind the latter. Since the outbreak of the pandemic, financial markets have been fluctuating dramatically, causing investors to raise concerns over risks and enhance awareness of risk prevention. However, with the easing of global financial conditions, investors have regained their appetite for risk, particularly in emerging economies [6].

\section{Literature Review}

As the pandemic progresses, an extensive literature theoretically and empirically lays out to what extent and in what way it impacts the financial markets worldwide. This catastrophe inflicts losses on investors since the ever-increasing confirmed cases and death toll have a negative influence on the stock market [7], the reaction of which is more to growth in the number of confirmed cases rather than that of deaths [8]. However, reference [9] suggests that the adverse impacts on emerging stock markets will gradually subside until it becomes statistically insignificant over the sample period. Reference [10] highlights that the negative effects are not persistent, but have bidirectional spillover effects between countries on different continents.

Reference [11] investigates global financial markets amid the pandemic with a large panel data set, finding that (i) OECD economies' daily depreciation of the exchange rate vis-à-vis the US dollar is positively influenced by growth in death toll, whose effects taper off due partly to the convergence trend. (ii) As far as long-term bond spreads are concerned, the shock due to a rising death toll resulted in a drastic upward trend in the acceleration phase of the pandemic (February through April) in EMEs. Later, the spreads were immune to death rate in the deceleration stage (April through June), irrespective of being EMEs or advanced economies. Reference [12] steps forward in providing a novel channel that helps predict exchange rate returns and volatility by using cumulative confirmed cases and deaths, both of which are fairly effective in the particular scenarios. Using the total 
confirmed cases, volatility prediction outperforms returns prediction for a one-day ahead forecast horizon, while returns prediction is superior over a five-day forward forecast, and a similar conclusion applies to the death toll. All told, his empirical results make a convincing argument that COVID-19 has been producing profound impacts on the foreign exchange (FX) markets.

By employing the number of cases and deaths as proxy variables to capture the severity of pandemic, reference [13] asserts the COVID-19 pandemic took a toll on EME financial markets that had experienced weakening currencies, rising spreads of credit default swaps (CDS), and declining equity valuations. Meanwhile, such effects resulted in a widening credit spread in advanced economies. Reference [14] sheds some light on traditional determinants that could bring about broadening divergence of spreads that seem inadequate to account for unusual phenomenon in Eurozone sovereign spreads during the pandemic. Their empirical results point to COVID-19 pandemic-related risks (e.g., mortality rate) and policies (e.g., Pandemic Emergency Purchase Program, PEPP) igniting these aberrant financial market behaviors.

Reference [15] suggests that a dramatic influence on the stock market cannot broadly be attributable to the fatality rate of the virus, quick dissemination of information, and global supply chains disruption, but a more plausible explanation seems to be that the preventive measures against COVID-19 proposed by governments imposed restrictions on personnel mobility and business activities (see also [16,17]). Reference [18] indicates that stock market stagnation has swept across many major economies, among which developed countries, including the UK and the US, have weathered the financial fallout slightly better than the Asian region, where financial markets are inundated with pessimistic and panic sentiments (see also [19]). Indeed, it is well documented that market sentiment interacts with the financial markets, as investors are not entirely irrational (see also [20]). The media is presently flooded with news reports related to COVID-19, subtly evoking a gamut of emotions. Interestingly, negative sentiments are prevailing [21], which possibly trigger a surging volatility and negative returns in the financial markets [22]. Reference [23] finds that, against the backdrop of soaring risk aversion, financial markets in EMEs are more susceptible to COVID-19 because of massive capital outflows. With regard to the magnitude of vulnerability, the bond market and stock market rank first and second, respectively, followed by the currency market. Reference [24] discusses that EME bond markets are overwhelmingly dependent on external portfolio investors, implying a weaker ability to insulate themselves from external shocks. As a consequence, local bond markets inevitably suffer from capital outflows and domestic currency depreciations, which further gives rise to a spike in bond spreads in the wake of COVID-19.

Reference [25] explores whether the contagion effect occurs across stock markets among a number of major economies during the pandemic. With a VARMA-GARCH-DCC model specification, they confirm that the listed financial companies are more closely interlinked than they were pre-pandemic. Reference [26] examines the pairwise volatility transmission between the BRIC nations and the US. The empirical results substantiate the presence of volatility spillovers and volatility persistence over short- and long-term.

\section{Data and Model Specification}

\subsection{Data and Preliminary Analyses}

Coincidentally, the Centers for Disease Control and Prevention (CDC) in both the US and South Korea reported the first confirmed case on January 20, both of which were associated with Wuhan, the center of pandemic outbreak in central China. Shortly thereafter, the cumulative number of confirmed cases has been showing an upward trend, particularly in the US. Numerous emergency countermeasures to curb the proliferation of COVID-19 were subsequently taken by both governments, such as physical and social distancing, selfisolation, and quarantine as well as travel restriction. In addition, South Korea implemented an extensive tracing and quarantine network. As public awareness of pandemic prevention 
continues to grow, the focus has shifted to the potential aftermath of COVID-19 that could trigger a financial depression or even financial meltdown in the future.

As illustrated in Figure 1, not until mid-to-late March had South Korea seen a slowdown in the coronavirus growth rate, which stood in sharp contrast to the US. At the onset of COVID-19 outbreaks, the US seemed not to be under siege from the virus as it achieved a plateau during the spring, which deteriorated into extensive chaos beyond imagination in the following two quarters.

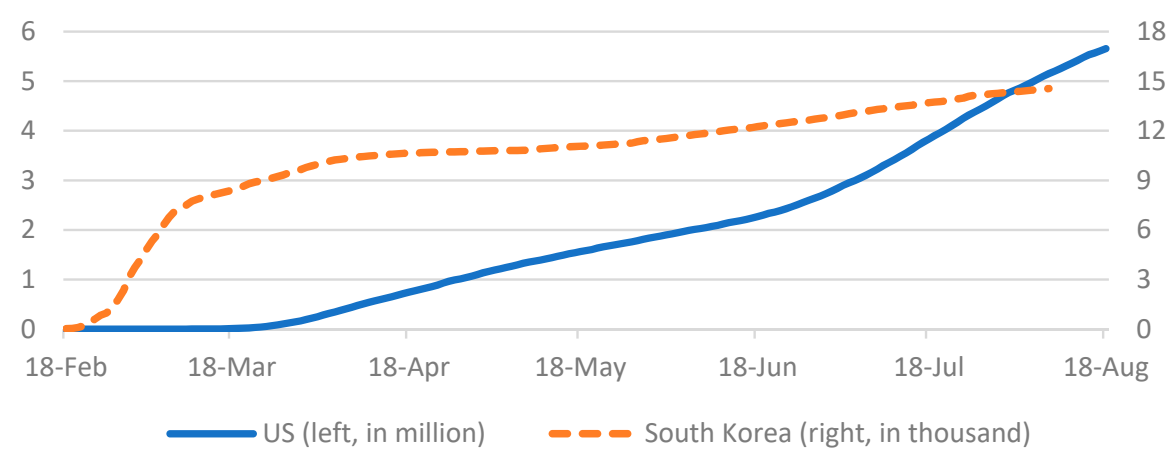

Figure 1. Data visualization for total confirmed cases.

Figure 2 plots that the stock market performance in the two countries moved in lockstep from a holistic perspective. Stock indices plunged precipitously during the first month, followed by a rapid rebound from the bottom to pre-pandemic level. The inflection points in the US and South Korean stock market took place on 23 March and 19 March, respectively.

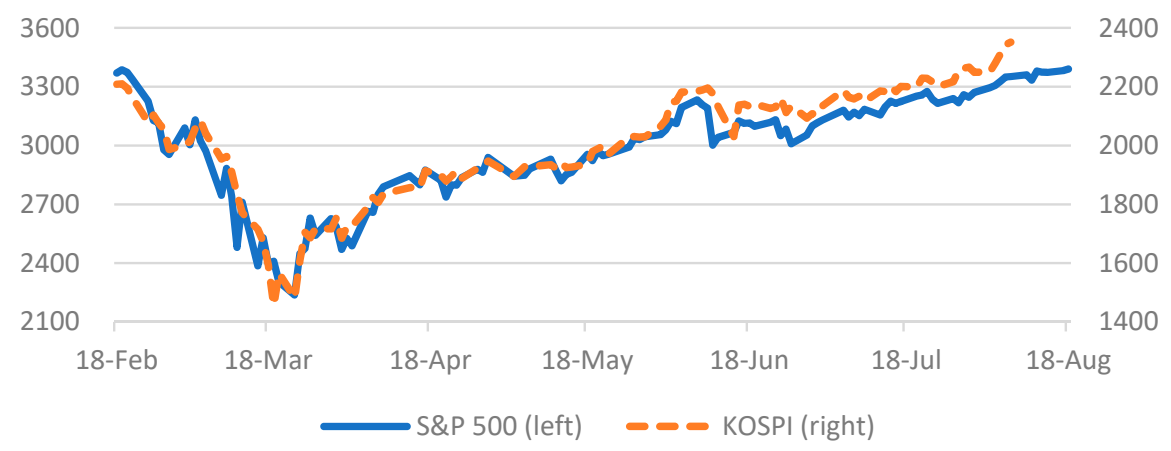

Figure 2. Data visualization for stock indices.

In the currency market, before the exchange rate continued to weaken, both the US dollar index and South Korean won were thrown into turmoil in the first half of sample period (see Figure 3). As expected, the currency value is negatively related with stock index, which is in accordance with portfolio balance theory.

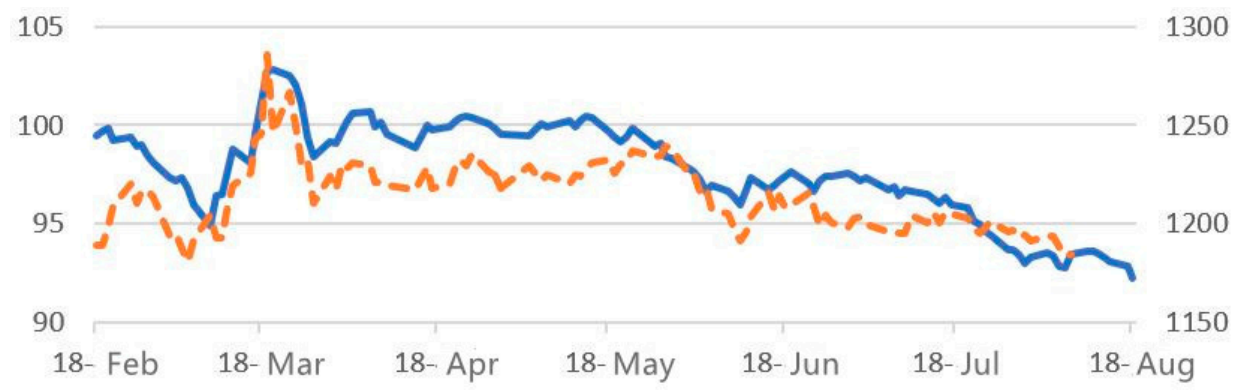

Figure 3. Data visualization for exchange rates.

The US TED spread presented a striking contrast to its counterpart, growing nearly tenfold in less than five weeks, then plummeting until returning to a pre-pandemic level 
early on in June. All the while, the TED spread (South Korea) oscillated back and forth within a relatively small range, reaching a peak of 0.351 on 9 April followed by a sustained decline, as shown in Figure 4.

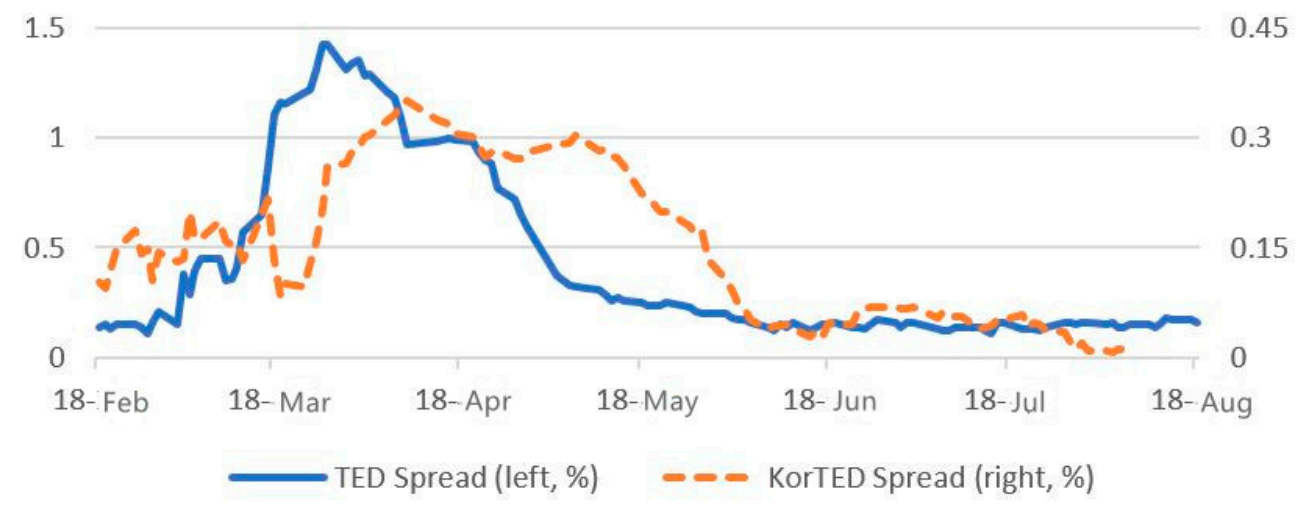

Figure 4. Data visualization for TED spreads.

In this study, we employ total confirmed cases to capture the severity of the ongoing COVID-19 pandemic, as does a considerable body of literature. Regarding financial markets, several indicators are taken into account, including the stock index, the exchange rate, as well as the spreads of the short-term bond against risk-free bonds. To be precise, the S\&P 500 and Korea Composite Stock Price Index (KOSPI) were taken to represent the US and South Korean stock markets, respectively. The exchange rate of the South Korean won against the US dollar is in direct quotation, and the US dollar index acts a proxy for the price of the dollar. The TED spread (US) is ready-to-use, while the TED spread (South Korea) is calculated in a similar way as follows:

TED spread (South Korea) = 3-month KORIBOR rate - 3-month MSBs rate

Korea Interbank Offered Rates (KORIBOR), a South Korean version of LIBOR, are renewed on a daily basis after calculating the average interest rates of term deposits at 15 financial institutions, including commercial lenders, policy banks, and branches of foreign banks. Monetary stabilization bonds (MSBs) are issued by the Bank of Korea (BOK), normally being considered risk-free. As to the data source, pandemic-specific series are obtained from Worldometer, and data related to South Korean financial markets are from the Economic Statistics System (ECOS BOK). The S\&P 500 and US dollar index are taken from Bloomberg, while the TED spread (US) is from the Federal Reserve Bank of St. Louis. Except for the TED spread, we first converted raw series (To ensure growth in confirmed cases, have same order of magnitude, both $u s a_{-} g r$ and kor_gr are not multiplied by 100) to log percentage returns as below, then labeled new series with a suffix '_gr'.

$$
R t=100.0 \times[\ln (P t / P t-1)]
$$

There is a mismatch between confirmed cases data and financial time series in terms of data accessibility due to the presence of non-trading days in the financial markets. Therefore, cumulative cases reported on the non-trading days are excluded. Additionally, ted_d and korted_d are computed as the first difference based on TED spread (US) and TED spread (South Korea), respectively. Of particular note is that $u s a \_g r$ and kor_gr are compared with the previous day rather than the previous trading day, which applies to the rest of the variables. It is a given that explosive growth in confirmed cases at the initial stage could cause outliers. Moreover, the South Korean TED spread became negative starting from mid-August, coupled with obvious inflection points of the total confirmed cases in two countries, so the data at both ends have been truncated. Consequently, the sample period for the US is from 18 February through 17 August 2020, with a total of 
124 daily observations. On the other hand, the dataset of 114 observations from South Korea spanned a period from 18 February to 7 August 2020.

The Jarque-Bera (JB) test is a goodness-of-fit test of whether the data is normally distributed. The further the JB statistic is from zero, the more the data deviates from a normal distribution. The normal distribution is characterized by a kurtosis of three and a skewness of zero. As seen in Tables 1 and 2, all financial series appear to be volatile and leptokurtic, which can be found as well in $u s a_{-} g r$ and kor_gr. More concretely, the average return of the South Korean stock market is higher than that of the US stock market over the sample period. Somewhat surprisingly, the mean values in both of the return series are positive, which may not be intuitive. With regard to FX markets, returns are negative but the South Korean won exhibits more volatility with a smaller mean and a greater standard deviation. The mean of korted_d is negative, as opposed to ted_d, but both are near-zero. The US, with an average daily growth in infections of $7.75 \%$, is one of the worst-hit countries. The analogous value for South Korea is less than half that of the US, benefiting from more stringent and comprehensive prevention measures against COVID-19.

Table 1. Descriptive statistics (US) ${ }^{1}$.

\begin{tabular}{|c|c|c|c|c|}
\hline Statistics & $u s a_{-g} r^{2}$ & $s p \_g r^{3}$ & $u s d \_g r{ }^{4}$ & $t e d \_d^{5}$ \\
\hline Mean & 0.0775 & 0.0028 & -0.0553 & 0.0002 \\
\hline Std. Dev & 0.1264 & 2.9356 & 0.5494 & 0.0551 \\
\hline Min. & 0.0000 & -12.7652 & -1.6946 & -0.12 \\
\hline Max. & 0.8473 & 8.9683 & 1.5880 & 0.24 \\
\hline Skewness & $2.8232 * * * 6$ & $-0.6561^{* * *}$ & $0.5825^{* * *}$ & $1.6102 * * *$ \\
\hline Kurtosis & $13.9189^{* * *}$ & $7.3560 * * *$ & $4.5121 * * *$ & $9.3799 * * *$ \\
\hline $\mathrm{JB}^{7}$ & $786.9958^{* * *}$ & $106.9322^{* * *}$ & $18.8261^{* * *}$ & $263.8867^{* * *}$ \\
\hline $\mathrm{ADF}^{8}$ & $-4.5872 * * *$ & $-16.3603^{* * *}$ & $-8.8360 * * *$ & $-7.9770^{* * *}$ \\
\hline $\mathrm{PP}^{9}$ & $-4.4350 * * *$ & $-15.6932^{* * *}$ & $-8.9813^{* * *}$ & $-8.4154^{* * *}$ \\
\hline $\mathrm{Q}(24)^{10}$ & $317.77 * * *$ & $55.90 * * *$ & 27.55 & $43.68 * * *$ \\
\hline $\mathrm{Q}^{2}(24)^{11}$ & $81.10 * * *$ & $132.30^{* * *}$ & $145.42 * * *$ & $75.83^{* * *}$ \\
\hline$\widehat{A R C H}(12){ }^{12}$ & $123.08^{* * *}$ & $5.64^{* * *}$ & $6.39 * * *$ & $7.07^{* * *}$ \\
\hline Obs. & 124 & 124 & 124 & 124 \\
\hline
\end{tabular}

${ }^{1}$ Sample period is from February 18 through August 17, 2020. ${ }^{2}$ Log return of cumulative confirmed cases in the US. ${ }^{3}$ Log return of stock market index (S\&P 500). ${ }^{4}$ Log return of dollar index spot. ${ }^{5}$ The first difference of TED spread. $6 *, * *, * *$ denote the rejection of null hypotheses at $10 \%, 5 \%$, and $1 \%$, respectively. ${ }^{7}$ Jarque-Bera statistic for normality test. ${ }^{8}$ Augmented Dickey-Fuller test for unit root. ${ }^{9}$ Phillips-Perron test for unit root. ${ }^{10}$ Modified Ljung-Box test for autocorrelation, robust to heteroscedasticity. ${ }^{11} \mathrm{McLeod}-\mathrm{Li}$ test for autocorrelation on the squares. ${ }^{12}$ ARCH-LM test for conditional homoscedasticity. Source: compiled by the authors.

Table 2. Descriptive statistics (South Korea) ${ }^{1}$.

\begin{tabular}{|c|c|c|c|c|}
\hline Statistics & kor_gr ${ }^{2}$ & $k o s p i \_g r^{3}$ & $k r w_{-g} r^{4}$ & korted_d ${ }^{5}$ \\
\hline Mean & 0.0372 & 0.0549 & -0.0035 & -0.0008 \\
\hline Std. Dev & 0.1148 & 2.3263 & 0.7508 & 0.0202 \\
\hline Min. & 0.0002 & -8.7670 & -3.0964 & -0.0850 \\
\hline Max. & 0.8157 & 8.2513 & 3.1606 & 0.0640 \\
\hline Skewness & $4.8271^{* * * 6} 6$ & -0.1150 & -0.0456 & -0.0019 \\
\hline Kurtosis & $29.4656^{* * *}$ & $6.1322 * * *$ & $7.2666^{* * *}$ & $6.6365^{* * *}$ \\
\hline $\mathrm{JB}^{7}$ & $3802.8182^{* * *}$ & $46.8532 * * *$ & $86.5080 * * *$ & $62.8155^{* * *}$ \\
\hline $\mathrm{ADF}^{8}$ & $-4.0306^{* * *}$ & $-11.2090 * * *$ & $-14.4822 * * *$ & $-9.5571^{* * *}$ \\
\hline $\mathrm{PP}^{9}$ & $-3.5507^{* * *}$ & $-11.3453^{* * *}$ & $-14.0498^{* * *}$ & $-9.6932^{* * *}$ \\
\hline $\mathrm{Q}(24)^{10}$ & $101.51^{* * *}$ & 14.16 & 26.97 & 22.22 \\
\hline $\mathrm{Q}^{2}(24)^{11}$ & $50.99 * * *$ & $116.93^{* * *}$ & $64.15^{* * *}$ & $65.87^{* * *}$ \\
\hline $\operatorname{ARCH}(12)^{12}$ & $6596.06^{* * *}$ & $11.07^{* * *}$ & $4.28^{* * *}$ & $2.92 * * *$ \\
\hline Obs. & 114 & 114 & 114 & 114 \\
\hline
\end{tabular}

${ }^{1}$ Sample period is from February 18 through August 17, 2020. ${ }^{2}$ Log return of cumulative confirmed cases in South Korea. ${ }^{3}$ Log return of stock market index (KOSPI). ${ }^{4}$ Log return of exchange rate of Korean won against US dollar. ${ }^{5}$ The first difference of Korean TED spread. $6 *$, ***** denote the rejection of null hypotheses at $10 \%$ $5 \%$, and $1 \%$, respectively. ${ }^{7}$ Jarque-Bera statistic for normality test. ${ }^{8}$ Augmented Dickey-Fuller test for unit root. ${ }^{9}$ Phillips-Perron test for unit root. ${ }^{10}$ Modified Ljung-Box test for autocorrelation, robust to heteroscedasticity.

${ }^{11}$ McLeod-Li test for autocorrelation on the squares. ${ }^{12}$ ARCH-LM test for conditional homoscedasticity. Source: compiled by the authors. 
We conducted both ADF and PP tests to examine the presence of unit root. The results are consistent in that all series are stationary at a $1 \%$ significance level. Modified Ljung-Box Q test and McLeod-Li test display that most series are not serially independent in both level and quadratic terms. ARCH-LM tests reject the null hypothesis of conditional homoscedasticity, suggesting the presence of ARCH effects in all series.

\subsection{Conditional Mean Equation}

By specifying a conditional mean model in order to remove linear dependence, the variance will be adequately captured for further analysis [27]. To our knowledge, defining a mean model with intercepts only is the simplest approach to ensure that the 'filtered' residuals are serially uncorrelated individually and have no correlation with the lags of the other components. Besides, a broad set of models are feasible, such as AR, VAR, ARMA, ARIMA, VARMA, etc. The following advantages motivate us to employ Vector Autoregression (VAR) as the mean model in this study. Firstly, it is possible to estimate the dynamic relationship among endogenous variables without a priori. Secondly, we can perform post estimation tests based upon preliminary results. For instance, impulse response functions (IRFs) provide a much easier channel to demonstrate how the system reacts to specific isolated shocks. Thirdly, the composite model locally converges to a stable solution. The basic $\operatorname{VAR}(p)$ equation takes the form:

$$
y t=c+\Phi_{1} y t-1+\Phi_{2} y t-2+\ldots+\Phi_{p} y t-p+H x t+\varepsilon_{t} \quad \mathrm{t}=1,2, \ldots, \mathrm{T}
$$

where $y_{t-p}$ denotes $p$ th-lag of endogenous variables $\left(y_{t}\right)$, and $c$ represents a $k$-vector of the constants serving as the intercept of the model. $\Phi_{1}, \ldots, \Phi_{p}$ and $H$ are time-invariant matrices $\left(k^{*} k\right)$, and a coefficient matrix $\left(k^{*} d\right)$ to be estimated, respectively. $x_{t}$ indicates a $d$-vector of exogenous variables. $\varepsilon_{t}$ is a $k$-vector of error terms which must satisfy three conditions: (i) Every error term has a mean of zero. (ii) The contemporaneous covariance matrix of error terms is a positive-semidefinite matrix $\left(k^{*} k\right)$, denoted $\Sigma$. (iii) There is no serial correlation in individual error terms.

\subsection{Conditional Variance Equation}

Unlike common time series, heteroscedasticity and volatility clustering can generally be observed on financial data. We convert levels to log-returns, one of variance stabilizing transformations to eliminate the heteroscedasticity, albeit not thoroughly. Fluctuations in the financial markets are associated closely with uncertainty, which possibly results in leptokurtic distribution. In other words, both crests and troughs are likely to be continuous over a period of time. A large volatility is followed by a large volatility and vice versa for small volatilities.

To capture the aforementioned characteristics, autoregressive conditional heteroscedasticity $(\mathrm{ARCH})$ process was originally introduced by [28]. The GARCH model [29], a generalized form of $\mathrm{ARCH}$, is far more parsimonious than ARCH model since it has fewer parameters that allow for an infinite number of squared roots to influence the conditional variance. However, there are a few drawbacks to the standard GARCH model as follows [30]: (i) Given the presence of leverage effects, response of financial markets to a negative innovation tends to be more volatile than to a positive shock with the same magnitude. (ii) Empirical results will inevitably be biased if time series have non-Gaussian error distributions rather than the normal distribution. To tackle these problems, we take into consideration asymmetry and non-normality simultaneously in the following model specifications. Furthermore, as to multivariate GARCH, enforcing positive-definiteness of the conditional covariance matrices is always handicapped by numerical issues, on one hand. On the other hand, it fails to capture the relatively sophisticated relationship among variables, such as spillover effects (what we are most concerned about in this paper). To the best of our knowledge, the BEKK model proposed by [31] allows a wide range of 
interactions, while imposing the restriction that the conditional variance always be positive. The BEKK model can be written as:

$$
H t=C C^{\prime}+\sum_{j=1}^{q} \sum_{k=1}^{K} A_{k j}{ }^{\prime} \varepsilon_{t-j} \varepsilon_{t-j}{ }^{\prime} A_{k j}+\sum_{j=1}^{p} \sum_{k=1}^{K} B_{k j}{ }^{\prime} H_{t-j} B_{k j}
$$

where $C, A_{k j}$, and $B_{k j}$ are $N * N$ parameter matrices, and $C$ is a lower triangular matrix. More concretely, $C$ is a constant matrix, while $A$ and $B$ are coefficient matrices of ARCH effects and GARCH effects, respectively. The coefficient matrix $A$ is referred to as the reaction parameter, measuring the past returns to the current conditional variances (shock spillovers). The coefficient matrix $B$ can be interpreted as the persistence parameter, capturing the past conditional variance to the current conditional variances (volatility spillovers). The transpose of a matrix is denoted with a single quote (e.g., $A^{\prime}$ is the matrix transpose of the matrix $A$ ). $H$ denotes the time-varying variance and covariance matrix as to endogenous variables in the system. $\varepsilon$ represents coefficient matrix of the residuals which is derived from mean equations. $K$ governs the extent to which the generality of the process in Equation (4) can be approximated by a BEKK representation. To generate a parsimonious specification of BEKK, unless otherwise noted, $K$ in the following sections is assumed to be one.

Meanwhile, the asymmetric terms as shown below need to be added,

$$
D^{\prime} v_{t-j} v_{t-j}{ }^{\prime} D
$$

where $D$ is a $N^{*} N$ matrix, and forcibly positive semi-definite. We then employ the most commonly used specification that the lag length is set to be one. For a 1,1 model $(q=p=1)$, the full BEKK recursion is specified as follows:

$$
H t=C C^{\prime}+A^{\prime} \varepsilon_{t-1} \varepsilon_{t-1}^{\prime} A+B^{\prime} H_{t-1} B+D^{\prime} v_{t-1} v_{t-1}^{\prime} D
$$

More concretely, the variance of variable (market) $i(i \neq j)$ return has the form:

$$
\begin{aligned}
& \sigma_{i, t}^{2}=C(i, i)^{2}+A(i, i)^{2} \varepsilon_{i, t-1}^{2}+2 A(i, i) A(j, i) \varepsilon_{i, t-1} \varepsilon_{j, t-1}+A(j, i)^{2} \varepsilon_{j, t-1}^{2} \\
& +B(i, i)^{2} \sigma_{i, t-1}^{2}+2 B(i, i) B(j, i) \sigma_{i j, t-1}+B(j, i)^{2} \sigma_{j, t-1}^{2} \\
& +D(i, i)^{2} v_{i, t-1}^{2}+2 D(i, i) D(j, i) v_{i, t-1} v_{j, t-1}+D(j, i)^{2} v_{j, t-1}^{2}
\end{aligned}
$$

Similarly, the variance of variable (market) $j(j \neq i)$ return has the form:

$$
\begin{aligned}
& \sigma_{j, t}^{2}=C(j, i)^{2}+C(j, j)^{2}+A(i, j)^{2} \varepsilon_{i, t-1}^{2}+2 A(i, j) A(j, j) \varepsilon_{i, t-1} \varepsilon_{j, t-1}+A(j, j)^{2} \varepsilon_{j, t-1}^{2} \\
& +B(i, j)^{2} \sigma_{i, t-1}^{2}+2 B(i, j) B(j, j) \sigma_{i j, t-1}+B(j, j)^{2} \sigma_{j, t-1}^{2} \\
& +D(i, j)^{2} v_{i, t-1}^{2}+2 D(i, j) D(j, j) v_{i, t-1} v_{j, t-1}+D(j, j)^{2} v_{j, t-1}^{2}
\end{aligned}
$$

Subsequently, the covariance of the variable (market) $i$ and variable (market) $j$ returns can be written as:

$$
\begin{aligned}
& \sigma_{i j, t}=C(i, i) C(j, i) \\
& +A(i, i) A(i, j) \varepsilon_{i, t-1}^{2}+(A(i, j) A(j, i)+A(i, i) A(j, j)) \varepsilon_{i, t-1} \varepsilon_{j, t-1}+A(j, i) A(j, j) \varepsilon_{j, t-1}^{2} \\
& +B(i, i) B(i, j) \sigma_{i, t-1}^{2}+(B(i, j) B(j, i)+B(i, i) B(j, j)) \sigma_{i j, t-1}+B(j, i) B(j, j) \sigma_{j, t-1}^{2} \\
& +D(i, i) D(i, j) v_{i, t-1}^{2}+(D(i, j) D(j, i)+D(i, i) D(j, j)) v_{i, t-1} v_{j, t-1}+D(j, i) D(j, j) v_{j, t-1}^{2}
\end{aligned}
$$

In addition, the GARCH model is estimated by the maximum likelihood method, and the corresponding log-likelihood function is:

$$
\ln \ell(\theta)=\frac{-T N}{2} \ln (2 \pi)-\frac{1}{2} \sum_{t=1}^{T}\left(\ln \left|H_{t}\right|+\frac{1}{2} \varepsilon_{t}{ }^{\prime} H_{t} \varepsilon_{t}\right)
$$


where $T$ denotes the number of observations; $\theta$ is the parameter to be estimated. It is worth noting that the calculation of $H_{t}$ is based on a combination of preliminary simplex iterations, following the BFGS numerical optimization algorithm as suggested in [32].

To sum up, we define a VAR-GARCH-BEKK model with $t$ errors and asymmetric effects as the baseline specification. For a BEKK model, the number of parameters to be estimated is $(p+q+1) N^{2}+N(N+1) / 2$. In a quadruplex case $(N=4)$, coupled with shape coefficient, the model contains 59 parameters.

\section{Empirical Results}

To guarantee BEKK estimates give rise to a stable recursion, the eigenvalue stability condition is required to be satisfied. The sum of the $\mathrm{VECH} A$ and $B$ matrices have eigenvalues far less than one, implying that the model specifications are appropriate.

Besides, the model will be stationary if the following conditions are satisfied [33]. Firstly, both $\left[A(i, i)^{2}+B(i, i)^{2}\right]$ and $\left[A(j, j)^{2}+B(j, j)^{2}\right]$ must be less than one. Secondly, all diagonal elements must be statistically significant. Undoubtedly, the models are applicable in two scenarios. All the sums relatively stand off from one, suggesting that the volatility in all series shows a faster mean reversion.

\subsection{Estimation Results}

The lag length is chosen by the Schwarz information criterion (SIC) and Akaike information criterion (AIC), both of which slightly favor 1 over other numbers. Given that series are likely against the assumption of homoscedasticity, we make an attempt to set up a low-order VAR model with different lag length. Since various specifications fail to converge, the lag length $(p=1)$ is selected.

Conditional mean models are employed to analyze return spillover effects across different markets or within the same market. As shown in Table 3, confirmed cases are influenced by its own lag, exogenous to financial markets. In addition to its own impacts, the current stock market return depends on the one-period lagged growth in the number of confirmed infections and dollar index. There is no evidence of spillover effects from $u s a \_g r$ or ted_d to the FX market. ted_d is unaffected by itself as opposed to the other three variables, but depends solely on the past returns in stock market.

Table 3. Estimation results for the conditional mean model (US).

\begin{tabular}{ccccc}
\hline & $u s a \_g r^{\mathbf{1}}$ & $s p \_g r$ & usd_gr & ted_d \\
\hline \multirow{2}{*}{$u s a \_g r(-1)^{2}$} & $0.9074^{* * 3}$ & $-0.9492^{* *}$ & 0.4723 & 0.0477 \\
& $(6.5184)$ & $(-6.1370)$ & $(0.7262)$ & $(1.5645)$ \\
\hline \multirow{2}{*}{$s p \_g r(-1)$} & 0.0000 & $0.0784^{* *}$ & $-0.0714^{* *}$ & $0.0028^{* *}$ \\
& $(0.0047)$ & $(-2.0656)$ & $(-4.7035)$ & $(2.3542)$ \\
\hline \multirow{2}{*}{$u s d \_g r(-1)$} & -0.0012 & $-0.4127^{* *}$ & $0.1747^{* *}$ & 0.0008 \\
& $(-1.8914)$ & $(-4.0450)$ & $(4.0411)$ & $(0.1693)$ \\
\hline \multirow{2}{*}{$t e d \_d(-1)$} & -0.0262 & 3.5674 & -1.3637 & 0.0222 \\
& $(-1.8968)$ & $(1.1628)$ & $(-1.4815)$ & $(0.1949)$ \\
\hline
\end{tabular}

${ }^{1}$ Variables in the first row are dependent variables. ${ }^{2}$ Variables in the first column are independent variables.

$3 * *$ Significant at $5 \%$ or better, and $t$-values are in the parentheses. Constant terms are available on request. Source: compiled by the authors.

Taking a close look at off-diagonal elements, only unidirectional spillovers from confirmed infections to financial markets can be found, while there is a bidirectional linkage between the stock and FX market. Beyond that, no significant spillover effects are detected. Coupled with signs, escalating cases are expected to lower one-period-ahead stock market returns. A bullish (bearish) stock market will exacerbate (mitigate) ted_ $d$, to a certain extent. FX returns exhibit an inverse trajectory against the stock market. In other words, past positive returns in stock market are more likely to aggravate losses in the FX 
market in the current period, while negative returns in the stock market probably enhance yields in FX market.

In Equation (7) through (8), it is difficult to interpret the coefficients $A(i, i) A(j, i)$ and $A(i, j) A(j, j)$. A positive (negative) coefficient $B(i, i) B(j, i)$ or $B(i, j) B(j, j)$ indicates that there is a positive (negative) relationship between the past covariance of the two markets and the current variance of either market. With respect to $D(i, i) D(j, i)$ and $D(i, j) D(j, j)$, a positive value in the past period suggests that the simultaneous negative shocks to two markets would increase the variance of either market in the current period. The rest of the coefficients are mathematically expressed in quadratic terms, which means a positive impact on the variance of either market in the next period.

As far as the Equation (9) is concerned, a positive (negative) coefficient $A(i, i) A(i, j)$ indicates that a shock to market $i$ has a positive (negative) effect on the covariance of the two markets in the next period. Likewise, a positive (negative) coefficient $A(j, i) A(j, j)$ suggests that a shock to market $j$ would exert positive influence on the covariance of the two markets in the next period. However, the sum of $A(i, j) A(j, i)$ and $A(i, i) A(j, j)$ is ambiguous. Further, a positive (negative) coefficient $B(i, i) B(i, j)$ means that the variance of market $i$ is positively (negatively) correlated with the covariance of the two markets in the next period; and a positive (negative) coefficient $B(j, i) B(j, j)$ means that the variance of market $j$ is positively (negatively) correlated with the covariance of the two markets in the next period. Additionally, a positive sum of $B(i, j) B(j, i)$ and $B(i, i) B(j, j)$ suggests that the covariance of the two markets in the next period would rise and fall in lockstep with the covariance in the current period.

With a negative shock to the market $i$, a positive (negative) coefficient $D(i, i) D(i, j)$ means an increase (decrease) in the covariance of the two markets in the next period; and a positive (negative) value of $D(j, i) D(j, j)$ would drive up (pull down) the covariance of the two markets in the wake of a negative shock to the market $j$.

Conditional variance models are defined as the transmission of volatility from market to market, and the results related to the US are demonstrated in Table 4. As expected, the diagonal parameters in Matrix A are statistically significant, which provides sufficient evidence that the volatility in all series responds significantly to their own past innovations. As far as the magnitude is concerned, the past returns to the current conditional variances in FX market top the list, followed by confirmed cases, stock market, and TED spread (It can be derived by the quadratic terms of ARCH parameters). Furthermore, the present variance of confirmed cases depends merely on its own lagged innovations, as does the FX market. Past shocks in the stock market and TED spread have an effect on their own variances, and bi-directional ARCH effect between two markets can be inferred. Apart from the aforementioned, neither unidirectional nor bi-directional ARCH effect remains across the financial markets. As to the cross-market effects of shock spillovers from $u s a \_g r$ to financial market, the stock market is the most affected by the pandemic $\left[\left(A_{12}\right)^{2}\right]$, while the bond market is the least affected $\left[\left(A_{14}\right)^{2}\right]$.

According to GARCH parameters, we found that the responses of volatility in each series are significantly influenced by their own past volatility. To be more specific, the response of volatility in confirmed cases to its own past volatility is 0.5396 . The analogue values in the financial markets are 0.1421 (stock market), 0.3216 (FX market), and 0.0705 (TED spread), respectively. Additionally, there are no GARCH effects from confirmed cases to financial markets, and vice versa. Unlike ARCH parameters, the FX market's volatility is influenced by previous volatility in stock market, TED spread, and its own market simultaneously. The growth rate in the dollar index tends to fluctuate more intensely under the volatility shock from TED spread. 
Table 4. Estimation results for the conditional variance model (US).

\begin{tabular}{|c|c|c|c|c|}
\hline \multicolumn{5}{|c|}{ Coefficient Matrix $\mathrm{A}^{1}$} \\
\hline & $u s a \_g r^{4}$ & $s p \_g r$ & $u s d \_g r$ & ted_d \\
\hline$u s a \_g r^{5}$ & $\begin{array}{c}0.5009 * * 6 \\
(6.0618)\end{array}$ & $\begin{array}{c}-5.7882 \\
(-1.7130)\end{array}$ & $\begin{array}{c}0.6879 \\
(0.8033)\end{array}$ & $\begin{array}{c}0.0457 \\
(1.1868)\end{array}$ \\
\hline$s p \_g r$ & $\begin{array}{c}0.0012 \\
(3.6379)\end{array}$ & $\begin{array}{l}0.3220 * * \\
(3.0087)\end{array}$ & $\begin{array}{c}-0.0024 \\
(-0.1255)\end{array}$ & $\begin{array}{l}0.0059 * * \\
(2.5516)\end{array}$ \\
\hline$u s d \_g r$ & $\begin{array}{c}-0.0006 \\
(-0.6907)\end{array}$ & $\begin{array}{c}-0.1656 \\
(-0.3383)\end{array}$ & $\begin{array}{l}0.5262 * * \\
(3.7785)\end{array}$ & $\begin{array}{c}-0.0046 \\
(-0.5915)\end{array}$ \\
\hline ted_d & $\begin{array}{c}-0.0439 \\
(-2.8177)\end{array}$ & $\begin{array}{l}1.5285 * * \\
(2.6673)\end{array}$ & $\begin{array}{c}-1.9139 \\
(-1.4912)\end{array}$ & $\begin{array}{l}0.2874 * * \\
(3.2574)\end{array}$ \\
\hline \multicolumn{5}{|c|}{ Coefficient Matrix B ${ }^{2}$} \\
\hline & $u s a \_g r$ & $s p \_g r$ & $u s d \_g r$ & $t e d \_d$ \\
\hline$u s a \_g r$ & $\begin{array}{l}0.7346^{* *} \\
(14.1037)\end{array}$ & $\begin{array}{c}3.4173 \\
(1.2508)\end{array}$ & $\begin{array}{c}-0.1298 \\
(-0.2047)\end{array}$ & $\begin{array}{c}-0.0719 \\
(-1.0213)\end{array}$ \\
\hline$s p \_g r$ & $\begin{array}{c}-0.0002 \\
(-1.0371)\end{array}$ & $\begin{array}{l}0.3770 * * \\
(4.0286)\end{array}$ & $\begin{array}{l}0.0672 * * \\
(3.1975)\end{array}$ & $\begin{array}{l}-0.0032 \text { ** } \\
(-2.2644)\end{array}$ \\
\hline$u s d \_g r$ & $\begin{array}{c}-0.0001 \\
(-0.1338) \\
\end{array}$ & $\begin{array}{c}0.8245 \\
(1.4028) \\
\end{array}$ & $\begin{array}{l}0.5671^{* *} \\
(4.1280)\end{array}$ & $\begin{array}{c}-0.0146 \\
(-1.5931) \\
\end{array}$ \\
\hline ted_d & $\begin{array}{c}-0.0127 \\
(-1.0297) \\
\end{array}$ & $\begin{array}{l}-2.6293 * * \\
(-4.8774)\end{array}$ & $\begin{array}{l}2.9325^{* *} \\
(2.8019)\end{array}$ & $\begin{array}{l}0.2655^{* *} \\
(3.4167)\end{array}$ \\
\hline \multicolumn{5}{|c|}{ Coefficient Matrix $\mathrm{C}^{3}$} \\
\hline & $u s a_{-} g r$ & $s p \_g r$ & $u s d_{\_} g r$ & $t e d \_d$ \\
\hline$u s a \_g r$ & $\begin{array}{c}0.0676 \\
(0.4243) \\
\end{array}$ & $\begin{array}{c}8.8990 \\
(1.1790) \\
\end{array}$ & $\begin{array}{c}1.6199 \\
(0.8815) \\
\end{array}$ & $\begin{array}{c}-0.0950 \\
(-0.7678)\end{array}$ \\
\hline$s p \_g r$ & $\begin{array}{c}-0.0007 \\
(-1.6138)\end{array}$ & $\begin{array}{l}0.3932 * * \\
(2.8394)\end{array}$ & $\begin{array}{c}0.0124 \\
(0.4433)\end{array}$ & $\begin{array}{l}-0.0174 \\
(-4.7869)\end{array}$ \\
\hline$u s d_{-g} g r$ & $\begin{array}{c}0.0015 \\
(0.7963) \\
\end{array}$ & $\begin{array}{l}0.9410 * * \\
(4.0896)\end{array}$ & $\begin{array}{l}0.1317 * * \\
(2.6602)\end{array}$ & $\begin{array}{c}0.0222 \\
(1.6004)\end{array}$ \\
\hline ted_d & $\begin{array}{c}0.0015 \\
(0.0434)\end{array}$ & $\begin{array}{c}-1.8203 \\
(-1.5888)\end{array}$ & $\begin{array}{c}2.3162 \\
(0.8732)\end{array}$ & $\begin{array}{l}1.2659 * * \\
(4.7638)\end{array}$ \\
\hline & & & $\begin{array}{l}4.4900 * * \\
(5.0978)\end{array}$ & \\
\hline \multicolumn{2}{|c|}{ Usable obs. } & \multicolumn{3}{|c|}{123} \\
\hline \multicolumn{2}{|c|}{ Log likelihood } & \multicolumn{3}{|c|}{417.11} \\
\hline \multicolumn{2}{|c|}{ Multivariate $Q(10)^{7}$} & \multicolumn{3}{|c|}{$\begin{array}{c}135.68 \\
(0.9188)\end{array}$} \\
\hline \multicolumn{2}{|c|}{ Multivariate $\mathrm{ARCH}(2)^{7}$} & \multicolumn{3}{|c|}{$\begin{array}{l}237.38 * * \\
(0.0362)\end{array}$} \\
\hline
\end{tabular}

${ }^{1}$ Estimated ARCH parameters, see text for details. ${ }^{2}$ Estimated GARCH parameters, see text for details. ${ }^{3}$ Estimated asymmetric parameters, see text for details. ${ }^{4}$ Variables in horizontal lines are response variables. ${ }^{5}$ Variables in vertical lines are shock variables. ${ }^{6 * *}$ Significant at $5 \%$ or better, and $\mathrm{t}$-values are in the parentheses. ${ }^{7}$ Model diagnostics, see text for details. Constant terms are available on request. Source: compiled by the authors.

As to asymmetric parameters, financial series without exception are affected by their own asymmetric shocks. The volatility under a negative shock (bad news) is greater than that under a positive shock (good news) in that all coefficients are significantly positive. Interestingly, there is no evidence to substantiate asymmetric shock effects of confirmed COVID-19 cases on the financial markets-that is-whether the status quo of COVID-19 pandemic improves or worsens, it will not mitigate or intensify the volatility of financial market in the near future. In addition, the stock market is characterized by the FX market's 
asymmetric shocks. External shocks in the FX market have unidirectional asymmetric effects on TED spread. Note that the shape parameter is statistically significant at $1 \%$, implying the presence of fat-tailed conditional residuals. As mentioned earlier, if $u s a_{-} g r$ and individual financial market have simultaneous negative shocks, this would either increase or decrease financial markets' return variance. However, the coefficients $D(i, i) D(j, i)$ are all jointly insignificant.

The residuals from the model, in principle, should be neither serially correlated nor exhibit remaining $\mathrm{ARCH}$ effects. Both multivariate $\mathrm{Q}$ test and multivariate $\mathrm{ARCH}$ tests are diagnostics for the multivariate GARCH model and its variations. The former does not reject the null hypothesis, showing it to be serially uncorrelated. Despite the fact that the latter test fails to hold the adequacy of the model at conventional significance level, lack of evidence support misspecification under $1 \%$.

In the same vein, estimation results in Table 5 can be interpreted as follows: (i) Except for FX market returns, the rest of the series are affected by their own lags at $1 \%$ significance level. (ii) The growth rate in confirmed cases exerts mean spillover effects on financial markets and not vice versa, which implies the presence of unidirectional causality. (iii) Although the presently weaker South Korean won will fuel its stock market in the future, the inverse does not hold because the coefficient $(\varphi 23)$ is insignificant at the conventional level. (iv) There is a positive bi-directional spillover effect between the change rate in TED spread and stock market returns. (v) The FX market and TED spread are mutually exogenous in the system.

Table 5. Estimation results for the conditional mean model (South Korea).

\begin{tabular}{ccccc}
\hline & kor_gr $\mathbf{1}$ & kospi_gr & krw_gr & korted_d \\
\hline \multirow{2}{*}{ kor_gr $(-1)^{2}$} & $0.7699^{* * 3}$ & $-3.8705^{* *}$ & $1.1826^{* *}$ & $0.0501^{* *}$ \\
& $(17.2541)$ & $(-4.7280)$ & $(5.3525)$ & $(12.0992)$ \\
\hline \multirow{2}{*}{ kospi_gr(-1) } & 0.0002 & $0.2271^{* *}$ & -0.0277 & $0.0015^{* *}$ \\
& $(1.4467)$ & $(3.5843)$ & $(-1.2228)$ & $(2.0252)$ \\
\hline \multirow{2}{*}{ krw_gr(-1) } & 0.0005 & $0.5904^{* *}$ & -0.1396 & 0.0009 \\
& $(1.0127)$ & $(2.5666)$ & $(-1.6676)$ & $(0.3927)$ \\
\hline \multirow{2}{*}{ korted_d(-1) } & 0.0136 & $2.4461^{* *}$ & -4.7595 & $-0.3723^{* *}$ \\
& $(1.3831)$ & $(4.2186)$ & $(-1.7929)$ & $(-5.5050)$ \\
\hline
\end{tabular}

${ }^{1}$ Variables in the first row are dependent variables. ${ }^{2}$ Variables in the first column are independent variables $3 * *$ Significant at $5 \%$ or better, and $t$-values are in the parentheses. Constant terms are available on request. Source: compiled by the authors.

Consistent with the findings in the US, all diagonal elements in the upper panel (Table 6 ) are significant at $1 \%$, and confirmed cases exhibit exogeneity within the system. However, the linkage across financial markets in South Korea seems to be more interactive in terms of the significance of off-diagonal coefficients. With regard to GARCH effects, the only difference is the significance level of the persistence parameter $B(4,3)$.

Table 6. Estimation results for the conditional variance model (South Korea).

\begin{tabular}{|c|c|c|c|c|}
\hline \multicolumn{5}{|c|}{ Coefficient Matrix A ${ }^{1}$} \\
\hline & $k o r \_g r 4$ & $k o s p i \_g r$ & $k r w \_g r$ & korted_d \\
\hline$k o r \_g r^{5}$ & $\begin{array}{c}0.3763 * * 6 \\
(2.9510)\end{array}$ & $\begin{array}{c}4.3043 \\
(1.5990)\end{array}$ & $\begin{array}{c}-0.2670 \\
(-0.2075)\end{array}$ & $\begin{array}{c}-0.0082 \\
(-0.2978)\end{array}$ \\
\hline kospi_gr & $\begin{array}{c}-0.0004 \\
(-1.2727)\end{array}$ & $\begin{array}{l}-0.2179 * * \\
(-2.3734)\end{array}$ & $\begin{array}{c}-0.0483 \\
(-0.9407)\end{array}$ & $\begin{array}{c}0.0014 \\
(1.0051)\end{array}$ \\
\hline$k r w \_g r$ & $\begin{array}{c}-0.0005 \\
(-0.6542)\end{array}$ & $\begin{array}{l}1.7848^{* *} \\
(4.6521)\end{array}$ & $\begin{array}{l}-0.4871 * * \\
(-4.1335)\end{array}$ & $\begin{array}{l}-0.0108 \text { ** } \\
(-2.1226)\end{array}$ \\
\hline korted_d & $\begin{array}{c}-0.0163 \\
(-1.0089)\end{array}$ & $\begin{array}{l}-6.0827^{* *} \\
(-6.0608)\end{array}$ & $\begin{array}{l}1.5547 * * \\
(3.6011)\end{array}$ & $\begin{array}{l}0.7658 * * \\
(5.5665)\end{array}$ \\
\hline
\end{tabular}


Table 6. Cont.

\begin{tabular}{|c|c|c|c|c|}
\hline \multicolumn{5}{|c|}{ Coefficient Matrix B ${ }^{2}$} \\
\hline & $k o r_{-} g r$ & kospi_gr & $k r w \_g r$ & korted_d \\
\hline$k o r \_g r$ & $\begin{array}{l}0.7040^{* *} \\
(10.5250)\end{array}$ & $\begin{array}{l}7.7063^{* *} \\
(2.3887)\end{array}$ & $\begin{array}{l}-2.5912 \\
(-1.5529)\end{array}$ & $\begin{array}{l}-0.0059 \\
(-0.1826)\end{array}$ \\
\hline kospi_gr & $\begin{array}{l}-0.0002 \\
(-1.2524)\end{array}$ & $\begin{array}{l}-0.0123 * * \\
(-2.0825)\end{array}$ & $\begin{array}{l}0.2455^{* *} \\
(3.9468)\end{array}$ & $\begin{array}{l}-0.0021 * * \\
(-2.8101)\end{array}$ \\
\hline$k r w \_g r$ & $\begin{array}{l}-0.0005 \\
(-1.2559)\end{array}$ & $\begin{array}{l}-0.2809 \\
(-0.4379)\end{array}$ & $\begin{array}{l}0.7306^{* *} \\
(3.2117)\end{array}$ & $\begin{array}{c}0.0005 \\
(0.1509)\end{array}$ \\
\hline korted_d & $\begin{array}{c}0.0176 \\
(1.7510)\end{array}$ & $\begin{array}{l}3.3857^{* *} \\
(5.7817)\end{array}$ & $\begin{array}{l}-5.3707 \\
(-1.8492)\end{array}$ & $\begin{array}{l}0.3163^{* *} \\
(5.6875)\end{array}$ \\
\hline \multicolumn{5}{|c|}{ Coefficient Matrix $\mathrm{C}^{3}$} \\
\hline & $k o r_{-} g r$ & kospi_gr & $k r w \_g r$ & korted_d \\
\hline$k o r_{-} g r$ & $\begin{array}{l}-0.0425 \\
(-0.2682)\end{array}$ & $\begin{array}{l}-5.7733 \text { ** } \\
(-3.0604)\end{array}$ & $\begin{array}{l}1.9180^{* *} \\
(2.9866)\end{array}$ & $\begin{array}{l}0.5517^{* *} \\
(2.6858)\end{array}$ \\
\hline kospi_gr & $\begin{array}{c}-0.0001 \\
(-0.3795)\end{array}$ & $\begin{array}{l}0.7828^{* *} \\
(5.1744)\end{array}$ & $\begin{array}{l}-0.1418^{* *} \\
(-2.7060)\end{array}$ & $\begin{array}{l}0.0062 * * \\
(3.1779)\end{array}$ \\
\hline$k r w \_g r$ & $\begin{array}{c}0.0009 \\
(1.1814) \\
\end{array}$ & $\begin{array}{c}0.0804 \\
(0.1332) \\
\end{array}$ & $\begin{array}{c}0.1847 \\
(0.9146)\end{array}$ & $\begin{array}{c}0.0007 \\
(0.1471) \\
\end{array}$ \\
\hline korted_d & $\begin{array}{l}-0.0177 \\
(-1.0271) \\
\end{array}$ & $\begin{array}{c}2.5837 \\
(1.8871) \\
\end{array}$ & $\begin{array}{l}-1.7910^{* *} \\
(-3.4814)\end{array}$ & $\begin{array}{l}-0.6161^{* *} \\
(-3.6388)\end{array}$ \\
\hline \multicolumn{2}{|c|}{ Shape } & \multicolumn{3}{|c|}{$\begin{array}{l}7.9750 * * \\
(3.7512)\end{array}$} \\
\hline \multicolumn{2}{|c|}{ Usable obs. } & \multicolumn{3}{|c|}{113} \\
\hline \multicolumn{2}{|c|}{ Log likelihood } & \multicolumn{3}{|c|}{612.46} \\
\hline \multicolumn{2}{|c|}{ Multivariate $Q(10)^{7}$} & \multicolumn{3}{|c|}{$\begin{array}{c}165.79 \\
(0.3605)\end{array}$} \\
\hline \multicolumn{2}{|c|}{ Multivariate $\mathrm{ARCH}(2)^{7}$} & \multicolumn{3}{|c|}{$\begin{array}{l}250.30^{* *} \\
(0.0101)\end{array}$} \\
\hline
\end{tabular}

${ }^{1}$ Estimated ARCH parameters, see text for details. ${ }^{2}$ Estimated GARCH parameters, see text for details. ${ }^{3}$ Estimated asymmetric parameters, see text for details. ${ }^{4}$ Variables in horizontal lines are response variables. ${ }^{5}$ Variables in vertical lines are shock variables. ${ }^{6 * *}$ Significant at $5 \%$ or better, and $t$-values are in the parentheses. ${ }^{7}$ Model diagnostics, see text for details. Constant terms are available on request. Source: compiled by the authors.

Particular attention will be paid to asymmetry. The lower panel demonstrates financial markets are closely related to spreading the trend of the COVID-19 pandemic. More precisely, in comparison with a positive event (e.g., a major breakthrough made in vaccine R\&D), an unanticipated negative shock to confirmed cases (e.g., cluster infection) could spark greater fluctuations in the financial markets.

\subsection{Impulse Response Functions (IRFs)}

Despite generalized impulse response functions (GIRFs) [34] being invariant to the ordering of the variables, the results are subject to strict assumptions. To prevent misleading statistical inference [35], we employ the IRFs to map out how the system reacts to specific isolated shocks. Prior to orthogonalization of the covariance matrix, we need to be satisfied that the residuals are correlated. On the one hand, the confirmed cases empirically and theoretically have an impact upon financial markets, and not vice versa. On the other hand, the transmission mechanism across financial markets is ambiguous. Consequently, with the Choleski factorization in the following order: growth rate in confirmed cases, stock market returns, FX market returns followed by change rates in TED spread, Figures 3 and 4 demonstrate responses to a common shock with Monte Carlo error bands (Number of Monte Carlo draws is 10,000). Our results are robust since the IRFs with different orderings are quite similar (available upon request).

In the US, the response of the stock market to shocks in confirmed COVID-19 cases is positive but insignificant during the initial stage, then it reaches a trough on the next 
day followed by slight oscillation along the horizontal line. Given that all series are in percentages, a $1 \%$ shock to confirmed cases is likely to produce no more than a $0.75 \%$ response in the stock market over the sample period. Response of the dollar index to confirmed cases is barely significant throughout the whole period. With a $1 \%$ positive shock from confirmed cases, the TED spread begins to rise, and subsequently peak on the second trading day. The bond market is least affected by infections, hovering below $0.01 \%$ over the horizon (see Figure 5).
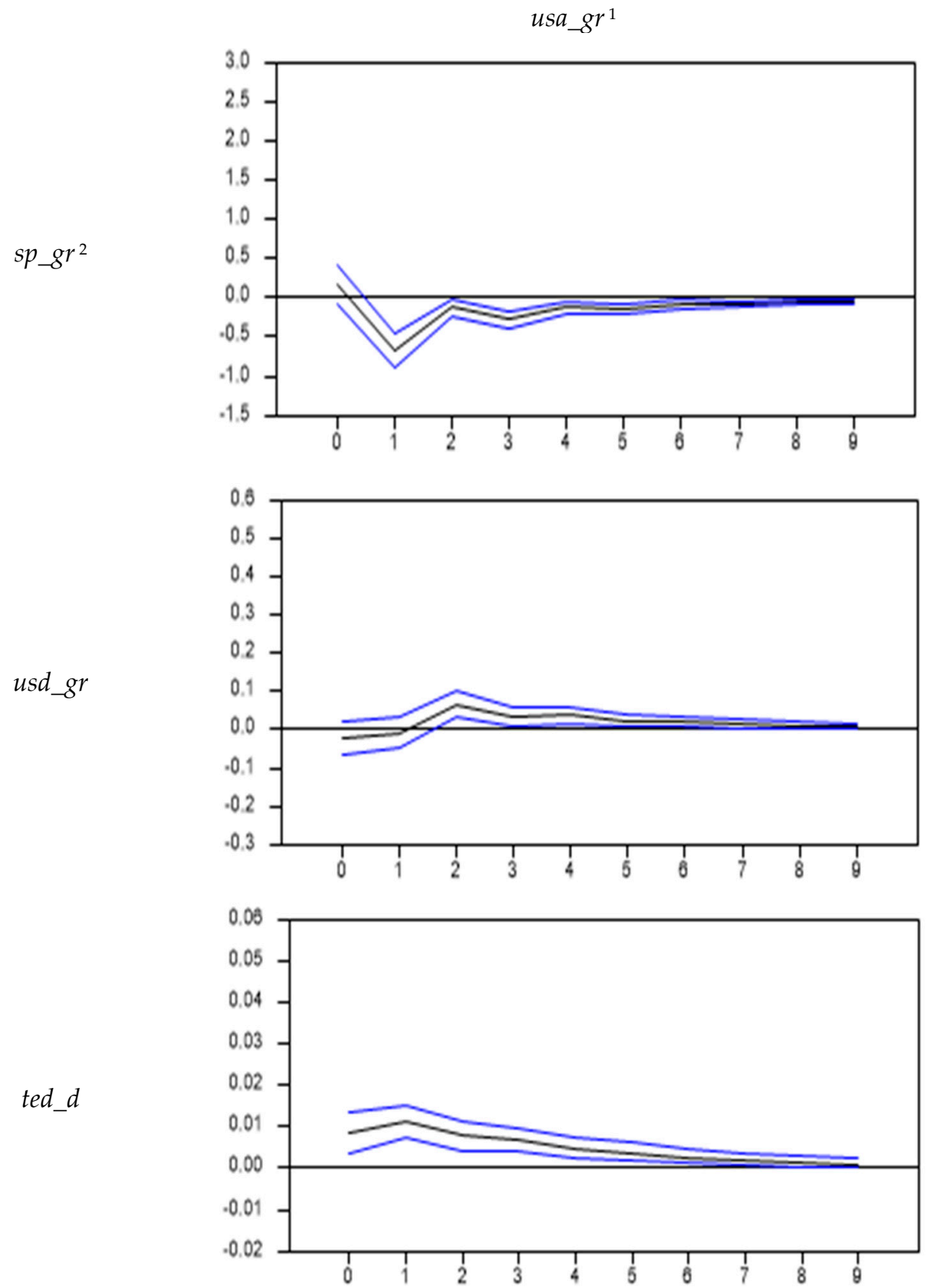

Figure 5. Impulse response functions with Monte Carlo error bands (US). ${ }^{1}$ Variable in the first row is the impulse variable. ${ }^{2}$ Variables in the first column are response variables.

As shown in Figure 6, the response of the South Korean stock market returns is significantly negative before dying out. On the other hand, the South Korean won undergoes an ascending trend, reflecting depreciation against US dollar. Confirmed cases have significant positive effects on TED spread, even though the response mildly and steadily declines from 
the second period. The response of the stock market $(-0.25 \%)$ is greater than the exchange rate $(0.10 \%)$, followed by TED spread $(0.003 \%)$ in terms of magnitude at the peak point.
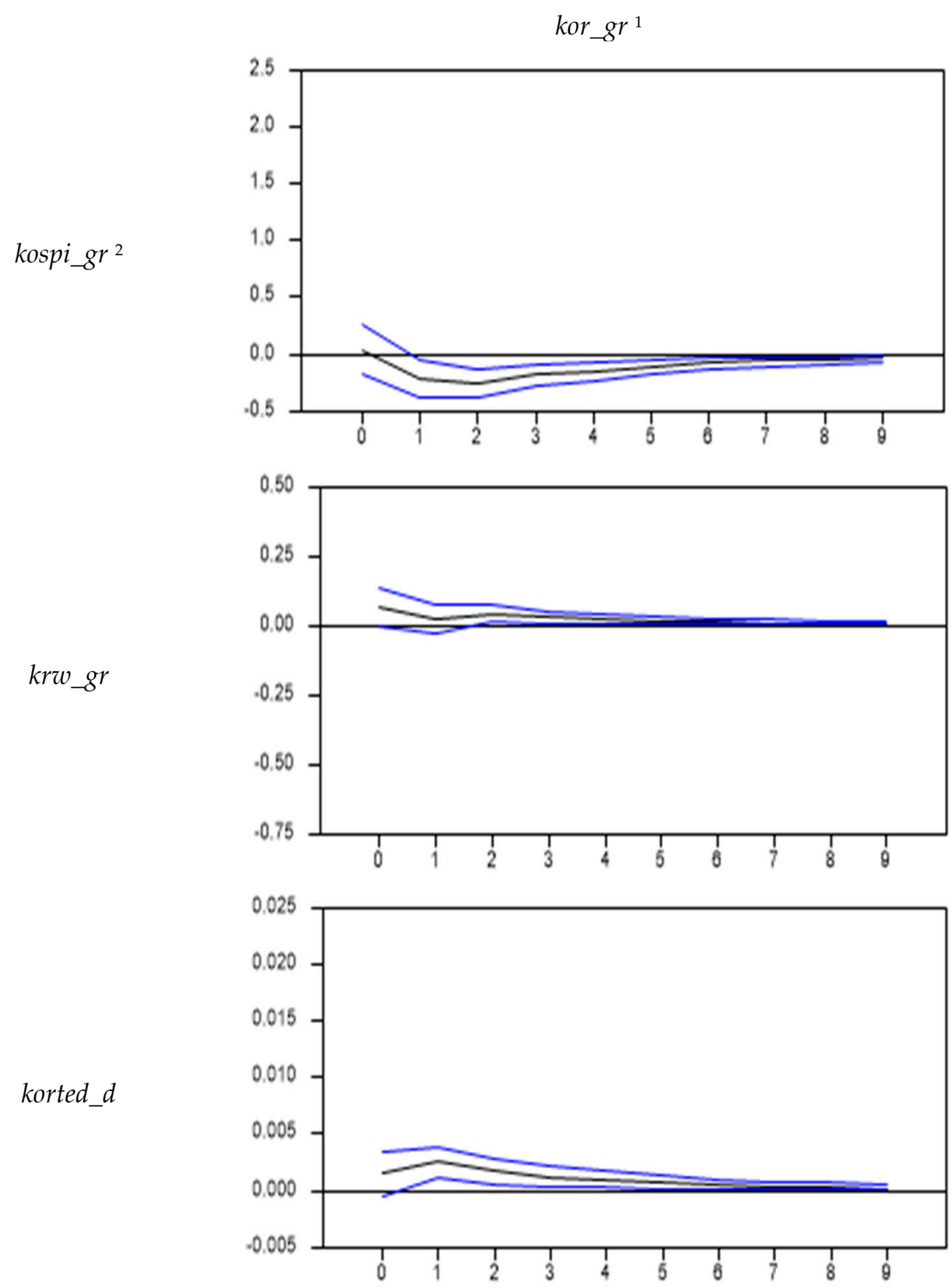

Figure 6. Impulse response functions with Monte Carlo error bands (US). ${ }^{1}$ Variable in the first row is the impulse variable. ${ }^{2}$ Variables in the first column are response variables.

Investment behavior is closely associated with investors' risk preferences and expectations of economic outlook, through which the pandemic plays a vital role in the financial markets. As risk aversion has spiked amid escalating concerns over uncertainty, a flight-tosafety episode is underway. Given this, countries considerably resilient to external shocks are more attractive to global capital flows, which is one of the main determinants driving the exchange rate. Conversely, financial markets being filled with pessimistic or panic sentiments stand a chance of a broad fear-driven sell-off, followed by currency depreciation. Similarly, domestic and foreign investors snapping up safe-haven financial assets could wreak havoc upon an economy, accompanied with a slump in stock returns and increasing credit spreads. This theoretical framework helps to explain what we observed under the onslaught of the COVID-19 pandemic. However, there is a major difference between two 
economies in the FX market. The depreciation of the South Korean won results in part from a capital outflow tsunami, which seems incapable of illustrating dollar index movements under innovations. One conceivable interpretation is that the liquidity unleashed by $\mathrm{QE}$ neutralizes a surging demand for the US dollar.

So far, the snowballing of confirmed cases and deaths related to COVID-19 have been amplifying panic among the public. Owing to great uncertainty over severity and duration, the extent of the impact which the ongoing pandemic will have on the global financial markets remains unclear. As previously discussed, chaos and turbulence in the time of COVID-19 are mainly in the form of descending stock indices, soaring credit premiums, and deteriorating liquidity in the FX markets, exposing the fragility of an economy [36]. Against this background, governments and central banks resort to fiscal stimulus package and monetary policy to insulate short-term disruptions from being trapped in long-lasting turmoil. However, maintaining a delicate balance between steady economic growth and financial markets stability is likely to be a puzzle to policymakers and regulators.

\section{Concluding Remarks}

This study has undertaken a full-scale comparison between the US and South Korea in the financial sector amid the COVID-19 pandemic. By applying the VAR-GARCH-BEKK model, our results confirm the presence of negative mean spillovers to the US and South Korean stock markets from the spread of the pandemic. In line with IRFs, the ongoing pandemic crisis will erode stock returns in the foreseeable future, though its long-run impacts dissipate within a certain period. The unidirectional mean spillover effects can be viewed from pandemic outbreaks to currency market and bond market in South Korea, an EME with relatively weak financial system soundness. However, from the perspective of coefficients in the conditional mean model, the US dollar and TED spread seem intact, thanks partly to synergy between liquidity drain and replenishment. Specifically, the trajectory of $u s d \_g r$ and ted_d corroborate dollar depreciation and widening TED spread under external shocks, respectively. Meanwhile, out of risk aversion, both the public and private sector are enthusiastic about purchasing dollar-denominated financial assets. There is little evidence to support the presence of volatility transmission from pandemic to financial markets in two countries.

The empirical results provide substantial evidence in the following areas. Firstly, South Korea seems more vulnerable since all financial markets are seen to be statistically associated with a growth in infections. Secondly, for the US, only the stock market is negatively impacted by confirmed cases in terms of the conditional mean spillover model. Thirdly, according to the impulse response functions (IRFs), apart from the US dollar index, both the TED spread and stock returns respond significantly to innovations from the pandemic. Lastly, there is little evidence to support the presence of volatility transmission from the pandemic to the financial markets in the two countries.

The US and South Korean governments took monetary and policy instruments to mitigate the adverse effects of the pandemic, which would precipitate a country going into a deeper recession. However, addressing an intricate issue generally comes at the cost of creating another. In the medium- and long-term, the expansionary policy would risk achieving overextended debt levels and high inflation rates, which will give rise to more uncertainties and increase vulnerability to external shocks in the future. Against the backdrop of pursuing expansionary policy in many countries, monetary authorities must stay vigilant against spillovers from other countries to prevent themselves from sliding into financial instability. Moreover, monetary policies should be eased or tightened to the correct degree on the one hand, and its transmission mechanism needs to be improved to maintain reasonably sufficient liquidity on the other. Policymakers should pay close attention to the interaction among financial markets, and make attempts to establish a long-run equilibrium between stable growth and risk prevention.

Author Contributions: All authors contributed equally to this work. All authors have read and agreed to the published version of the manuscript. 
Funding: This study received no external funding.

Institutional Review Board Statement: Not applicable.

Informed Consent Statement: Not applicable.

Data Availability Statement: MDPI Research Data Policies.

Conflicts of Interest: The authors declare no conflict of interest.

\section{References}

1. Ali, M.; Alam, N.; Rizvi, S.A.R. Coronavirus (COVID-19)—An epidemic or pandemic for financial markets. J. Behav. Exp. Financ. 2020, 27, 100341. [CrossRef] [PubMed]

2. Czech, K.; Wielechowski, M.; Kotyza, P.; Benešová, I.; Laputková, A. Shaking Stability: COVID-19 Impact on the Visegrad Group Countries' Financial Markets. Sustainability 2020, 12, 6282. [CrossRef]

3. Reinders, H.J.; Schoenmaker, D.; Van Dijk, M.A. Is COVID-19 a Threat to Financial Stability in Europe? CEPR Discussion Paper DP14922; Center for Economic Policy Research: London, UK, 2020; p. DP14922.

4. Bowman, D.; Londono, J.M.; Sapriza, H. US unconventional monetary policy and transmission to emerging market economies. J. Int. Money Financ. 2015, 55, 27-59. [CrossRef]

5. Chen, M.J.; Griffoli, M.T.M.; Sahay, M.R. Spillovers from United States Monetary Policy on Emerging Markets: Different This Time? International Monetary Fund: Washington, DC, USA, 2014; No. 14-240.

6. Amstad, M.; Cornelli, G.; Gambacorta, L.; Xia, F.D. Investors' Risk Attitudes in the Pandemic and the Stock Market: New Evidence Based on Internet Searches. BIS Bull. 2020, 25, 1-7. Available online: https://www.bis.org/publ/bisbull25.pdf (accessed on 10 May 2021).

7. Al-Awadhi, A.M.; Alsaifi, K.; Al-Awadhi, A.; Alhammadi, S. Death and contagious infectious diseases: Impact of the COVID-19 virus on stock market returns. J. Behav. Exp. Financ. 2020, 27, 100326. [CrossRef] [PubMed]

8. Ashraf, B.N. Stock markets' reaction to COVID-19: Cases or fatalities? Res. Int. Bus. Financ. 2020, 54, 101249. [CrossRef]

9. Topcu, M.; Gulal, O.S. The impact of COVID-19 on emerging stock markets. Financ. Res. Lett. 2020, 36, 101691. [CrossRef]

10. He, Q.; Liu, J.; Wang, S.; Yu, J. The impact of COVID-19 on stock markets. Econ. Political Stud. 2020, 8, 275-288. [CrossRef]

11. Esteves, R.; Sussman, N. Corona Spreads to Emerging Markets; Centre for Economic Policy Research: London, UK, 2020; Volume 1, pp. 362-373.

12. Iyke, N. The Disease Outbreak Channel of Exchange Rate Return Predictability: Evidence from COVID-19. Emerg. Mark. Financ. Trade 2020, 56, 2277-2297. [CrossRef]

13. Ahmed, S.; Hoek, J.; Kamin, S.B.; Smith, B.; Yoldas, E. The Impact of COVID-19 on Emerging Market Economies' Financial Conditions; FEDS Notes; No. 2020-10-07-1; Board of Governors of the Federal Reserve System: Washington, DC, USA, 2020.

14. Jinjarak, Y.; Ahmed, R.; Nair-Desai, S.; Xin, W.; Aizenman, J. Pandemic Shocks and Fiscal-Monetary Policies in the Eurozone: COVID-19 Dominance During January-June 2020; No. w27451; National Bureau of Economic Research: Cambridge, MA, USA, 2020.

15. Baker, S.R.; Bloom, N.; Davis, S.J.; Kost, K.J.; Sammon, M.C.; Viratyosin, T. The Unprecedented Stock Market Impact of COVID-19; No. w26945; National Bureau of Economic Research: Cambridge, MA, USA, 2020.

16. Ashraf, B.N. Economic impact of government interventions during the COVID-19 pandemic: International evidence from financial markets. J. Behav. Exp. Financ. 2020, 27, 100371. [CrossRef]

17. Ozili, P.K.; Arun, T. Economic Effects of Coronavirus Outbreak. 2020; preprint.

18. Liu, H.; Manzoor, A.; Wang, C.; Zhang, L.; Manzoor, Z. The COVID-19 outbreak and affected countries stock markets response. Int. J. Environ. Res. Public Health 2020, 17, 2800. [CrossRef]

19. Mishra, P.K.; Mishra, S.K. Corona Pandemic and Stock Market Behaviour: Empirical Insights from Selected Asian Countries. Millenn. Asia 2020, 11, 341-365. [CrossRef]

20. Shu, H.C.; Chang, J.H. Investor sentiment and financial market volatility. J. Behav. Financ. 2020, 16, 206-219. [CrossRef]

21. Aslam, F.; Awan, T.M.; Syed, J.H.; Kashif, A.; Parveen, M. Sentiments and emotions evoked by news headlines of coronavirus disease (COVID-19) outbreak. Humanit. Soc. Sci. Commun. 2020, 7, 1-9. [CrossRef]

22. Haroon, O.; Rizvi, S.A.R. COVID-19: Media coverage and financial markets behavior-A sectoral inquiry. J. Behav. Exp. Financ. 2020, 27, 100343. [CrossRef]

23. Beirne, J.; Renzhi, N.; Sugandi, E.A.; Volz, U. Financial Market and Capital Flow Dynamics During the COVID-19 Pandemic; No. 1158; Asian Development Bank Institute: Tokyo, Japan, 2020.

24. Hofmann, B.; Shim, I.; Shin, H.S. Emerging Market Economy Exchange Rates and Local Currency Bond Markets Amid the COVID-19 Pandemic; No. 5; Bank for International Settlements: Basel, Switzerland, 2020.

25. Akhtaruzzaman, M.; Boubaker, S.; Sensoy, A. Financial contagion during COVID-19 crisis. Financ. Res. Lett. 2021, 38 , 101604. [CrossRef] [PubMed]

26. Malik, K.; Sharma, S.; Kaur, M. Measuring contagion during COVID-19 through volatility spillovers of BRIC countries using diagonal BEKK approach. J. Econ. Stud. 2021, preprint.

27. Tsay, R.S. Analysis of Financial Time Series; John Wiley \& Sons: Hoboken, NJ, USA, 2005; Volume 543. 
28. Engle, R.F. Autoregressive Conditional Heteroskedasticity with Estimates of the Variance of U.K. Inflation. Econometrica 1982, 50, 987-1008. [CrossRef]

29. Bollerslev, T. Generalized autoregressive conditional heteroskedasticity. J. Econom. 1986, 31, 307-327. [CrossRef]

30. Zivot, E. Practical Issues in the Analysis of Univariate GARCH models. In Handbook of Financial Time Series; Springer: Berlin/Heidelberg, Germany, 2009; pp. 113-155.

31. Engle, R.F.; Kroner, K.F. Multivariate Simultaneous Generalized ARCH. Econom. Theory 1995, 11, 122-150. [CrossRef]

32. Doan, T.A. RATS Handbook for ARCH/GARCH and Volatility Models; Estima WINRATS: Evanston, IL, USA, 2013.

33. Schmitz, J.; von Ledebur, O. Approaches to assess higher dimensional price volatility co-movements. In Methods to Analyse Agriculture Commodity Price Volatility; Springer: New York, NY, USA, 2011; pp. 133-148.

34. Koop, G.; Pesaran, M.H.; Potter, S.M. Impulse response analysis in nonlinear multivariate models. J. Econom. 1996, 74, 119-147. [CrossRef]

35. Kim, H. Generalized impulse response analysis: General or Extreme? EconoQuantum 2013, 10, 136-141. [CrossRef]

36. Global Financial Stability Report; International Monetary Fund: Washington, DC, USA, 2020. 